\title{
Landmine Detection and Imaging Using Micropower Impulse Radar (MIR)
}

\author{
S. G. Azevedo \\ D. T. Gavel \\ J. E. Mast \\ J. P. Warhus
}

August 7, 1995

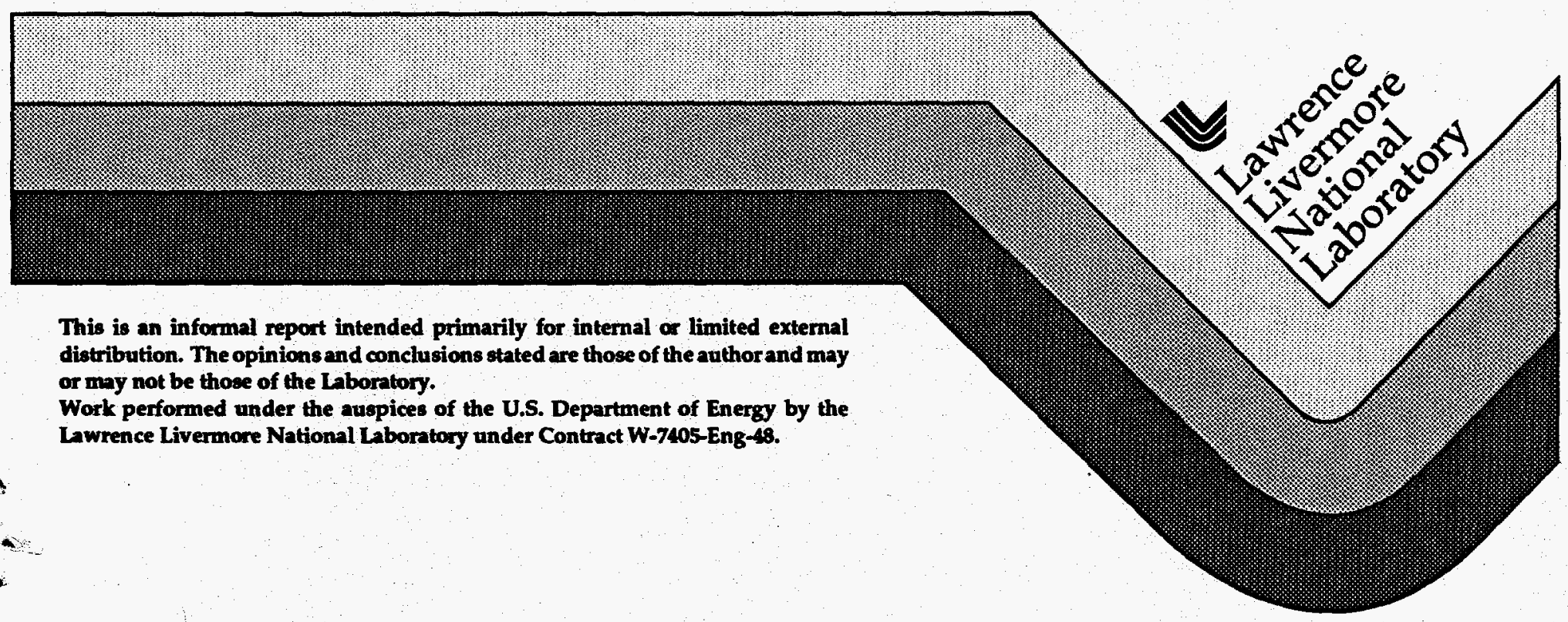




\section{DISCLAIMER}

This document was prepared as an account of work sponsored by an agency of the United States Government. Neither the United States Government nor the University of California nor any of their employees, makes any warranty, express or implied, or assumes any legal liability or responsibility for the accuracy, completeness, or usefulness of any information, apparatus, product, or process disclosed, or represents that its use would not infringe privately owned rights. Reference herein to any specific commercial product, process, or service by trade name, trademark, manufacturer, or otherwise, does not necessarily constitute or imply its endorsement, recommendation, or favoring by the United States Government or the University of California. The views and opinions of authors expressed herein do not necessarily state or reflect those of the United States Government or the University of California, and shall not be used for advertising or product endorsement purposes.

This report has been reproduced directly from the best available copy.

Available to DOE and DOE contractors from the Office of Scientific and Technical Information P.O. Box 62, Oak Ridge, TN 37831

Prices available from (615) 576-8401, FTS 626-8401

Available to the public from the National Technical Information Service

U.S. Department of Cormmerce 5285 Port Royal Rd., Springfield, VA 22161 


\section{DISCLAIMER}

Portions of this document may be illegible in electronic image products. Images are produced from the best available original document. 


\title{
Landmine Detection and Imaging using Micropower Impulse Radar (MIR)
}

\author{
S.G. Azevedo, D.T. Gavel, J.E. Mast, and J.P. Warhus \\ Lawrence Livermore National Laboratory \\ Imaging and Detection Program \\ P.O. Box 808, L-495 \\ Livermore, California 94551 \\ Phone: $510-422-8538$ \\ FAX: $510-422-3358$ \\ e-mail: azevedo3@llnl.gov
}

\begin{abstract}
The Lawrence Livermore National Laboratory (LLNL) has developed radar and imaging technologies with potential applications in mine detection by the armed forces and other agencies involved in demining efforts. These new technologies use a patented ultrawideband (impulse) radar technology that is compact, low-cost, and low power. Designated as Micropower Impulse Radar, these compact, self-contained radars can easily be assembled into arrays to form complete ground penetrating radar imaging systems. LLNL has also developed tomographic reconstruction and signal processing software capable of producing high-resolution 2-D and 3-D images of objects buried in materials like soil or concrete from radar data. Preliminary test results have shown that a radar imaging system using these technologies has the ability to image both metallic and plastic land mine surrogate targets buried in 5 to $10 \mathrm{~cm}$ of moist soil. In dry soil, the system can detect buried objects to a depth of $30 \mathrm{~cm}$ and more. This report describes our initial test results and plans for future work.
\end{abstract}

\subsection{Introduction}

The Micropower Impulse Radar (MIR) is a new class of radar because of its (1) low cost and small size, (2) low power requirements, and (3) ultra-wideband (impulse) frequency range. It has the ability to penetrate dielectric materials like wood, concrete, and soil and provide high resolution detection of changes in embedded material dielectric and conductivity properties. A single MIR module is a compact, light-weight, self-contained impulse radar transceiver constructed using low-cost, off-the-shelf components. The low level of radiated RF power ( $<100 \mathrm{~mW}$ peak and $<10 \mathrm{~mW}$ average) and wide bandwidth of the MIR module radiation ensure operator and equipment safety with respect to both RF exposure and ordnance safety concerns. A recent cover story of Popular Science (March 1995) focuses on the MIR and describes many of these applications.

The MIR has recently been tested to evaluate its viability as a mine detection sensor. These tests show that MIR reliably detects both plastic and metallic land mines and mine surrogates buried in both moist and dry soils. The MIR sensor technology provides several advantages

- Work performed under the auspices of the U.S. Department of Energy by Lawrence Livermore National Laboratory under contract No. W-7405-ENG-48. 
over existing ground-penetrating radar (GPR) systems [1] including: low cost, low power, lightweight and compact size, and the ability to assemble into compact arrays. Coupled with LLNL's 2-D and 3-D imaging algorithms, MIR offers the potential for a low cost, high performance mine detector that will enhance the reliability and performance of multisensor mine detection systems. This paper describes the new sensor technology and presents examples of its capabilities. In addition, it discusses results from the recent field tests and describes system concepts for vehicle mounted and hand-held mine detectors.

For mine detection and imaging, high resolution in both range and cross-range is required. High range resolution is achieved by the ultra-wide bandwidth of the MIR module. The short pulse rise-time of 100 ps yields range resolution of about $1 \mathrm{~cm}$ in typical soils. To achieve high cross-range resolution, an array of MIR elements can be assembled to form a large aperture. The miniature properties of the MIR module make it especially attractive to use in radar arrays. Alternatively, a single radar element collecting samples at evenly-spaced intervals along a line can be used to form a synthetic 1-D array. The resolution achieved depends on the element spacing and the overall dimension of the aperture. For example, we have used a one-meter aperture with one-centimeter spacing (100 synthetic array elements) to achieve cross range resolution of a few centimeters at ten-centimeters depth in soil. To achieve high resolution in two cross-range directions, it is necessary to form a 2-D array on the surface. This generates a full three-dimensional representation of a volume of ground, and can be accomplished by forming a synthetic array in both dimensions.

LLNL has developed unique imaging software for MIR arrays to provide for high-resolution imaging of buried objects [2]. The imaging software was developed for radar inspection of steel-reinforced concrete bridge decks. This new software does not require direct contact between the sensors and the bridge to obtain inspection data. As a result, the system can collect data over large areas very rapidly. Images reconstructed from the data will enable bridge engineers and inspectors to visualize structural details that were previously only observable using destructive techniques like coring. The radar imaging technology and system concepts developed for bridge deck inspection are directly applicable to the mine detection problem and to other underground imaging problems.

\subsection{MIR Mine Detection Feasibility Tests}

To evaluate the feasibility of using MIR as a mine detection sensor, we assembled a prototype MIR module into a test system that could be used to make measurements in the field. A single MIR module (with one transmitter and one receiver element) was used for collecting radar data, along synthetic 1-D and 2-D arrays in "look-down" operating mode. It was set up to move along a wooden frame with an air-gap over the ground to simulate a vehicle-mounted or hand-held array. To acquire 3-D data, the frame was moved in calibrated steps after each sensor pass. A lap-top computer with data acquisition hardware and software collected the radar data. The standoff height for the radar in look down mode varied from 3 to $30 \mathrm{~cm}$.

The field tests were conducted at the Buried Object and Mine Detection Facility at the Nevada Test Site (NTS) where real anti-tank and anti-vehicular mines (without detonators) and mine surrogates, both plastic and metallic, have been buried in known locations at this facility. Natural vegetation, rocks and rubble, and animal burrows were left intact when the mines were buried to maintain realistic conditions. The soil in the test area is made up of alluvium, consisting of Paleozoic fragments and tuff. Soil conductivity is in the range of 5 to 8 millisiemen. The soil was moist, due to rain from the day before, with a dry topmost layer of a few millimeters. 
Figure 1 show results from two different plastic anti-tank mines: the M-19 and VS-2.2 mines. The MIR sensor was scanned over a known M-19 mine location and reconstructed to obtain 3-D radar return data. Instead of the traditional B-scan or "waterfall" type display common in radar and ultrasonic imaging, we reconstructed the full 3-D volume to display various slices. Now we can display horizontal slices at various depths (Figure 1) to image the object as though peering down at it. Knowledge of the media (air/ground), the scan timing, and the scan geometry are needed to compute this image using diffraction tomography methods. A 486 lap-top computer reconstructs each 2-D slice image in less than ten seconds.

Results of the tests show conclusively that real metallic and plastic mines buried roughly 5 $\mathrm{cm}$ beneath the surface can be readily detected and imaged by the MIR system. Metal M-15 mines show a strong reflection from the top of the mine. Plastic M-19 and VS-2.2 mines show reflections from both top and bottom mine surfaces and a characteristic resonance behavior. Clutter and spurious returns are also visible in the $2-\mathrm{D}$ vertical slice due to buried rocks and other debris, but the dielectric difference between the plastic mine and soil is enough for reliable detection of the mine. We are currently conducting tests on the smaller anti-personnel mines with similar results. Imaging is expected to provide low false alarm rates because of this ability to distinguish shape. However, this must be confirmed by further field studies and statistical analyses.

Vehicle-mounted and man-portable mine detection systems are needed for demining operations in both low-and high-clutter environments. MIR arrays and image reconstruction software can be readily integrated into viable multisensor systems that address both these needs. These systems can be used for detection and marking of individual mines, for personnel assessment and training, and for quality assurance. Some modifications are required to adapt current MIR module technology for the various system concepts. For example, work is progressing on antenna and antenna lens designs to tailor antenna gain and radiation patterns for the needs of a variety of applications. These changes will permit MIR modules and arrays to operate at stand-off ranges required for vehicular and man-portable mine detection systems used in demining operations.

\subsection{Summary}

Minefield clearing is an important international humanitarian problem. MIR and radar imaging technology developed at LLNL have direct applicability to the demining problem. Our feasibility tests have shown that these technologies reliably detect and image both metallic and plastic mines, and that they offer the potential for classifying buried objects that could improve detection and decrease false alarm rates for multisensor mine detection systems. Imaging speed currently gives near-real-time results on a laptop computer, and is expected to improve with high-speed portable computers. Costs of such a system will be low, even with imaging capability, because hardware costs of the MIR are orders-ofmagnitude below current radar technology. Ongoing development activities at LLNL are addressing design changes that are needed to further improve current MIR technology to satisfy mine detection requirements.

\subsection{References}

[1] P.D. Sargis, F.D. Lee, E.S. Fulkerson, B.J. McKinley, W.D. Aimonetti, "GroundPenetrating Radar for Buried Mine Detection," SPIE Vol. 2217, Aerial Surveillance Sensing, including Obscured and Underground Object Detection, 4-6 April 1994.

[2] J.E. Mast, E.M. Johansson, "Three-dimensional ground penetrating radar imaging using multi-frequency diffraction tomography," SPIE Vol. 2275, Advanced Microwave and Millimeter Wave Detectors, 25-26 July 1994. 


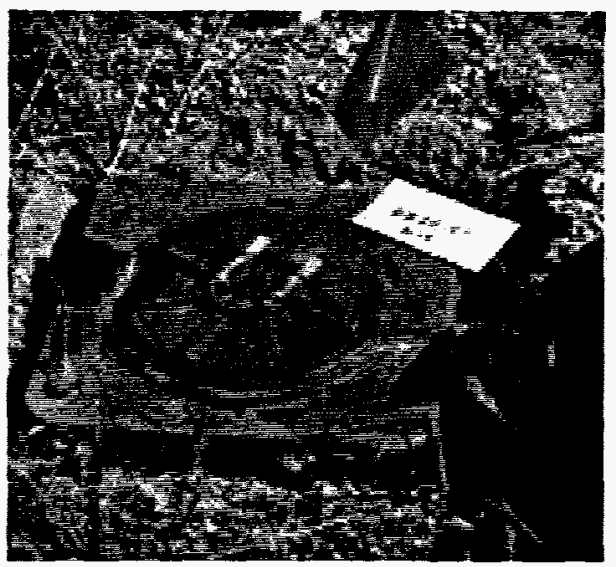

M-19

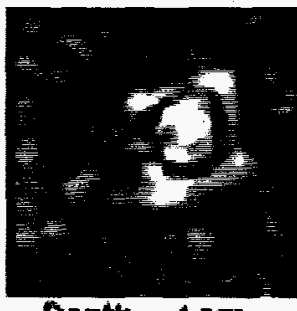

Depth $=4 \mathrm{~cm}$

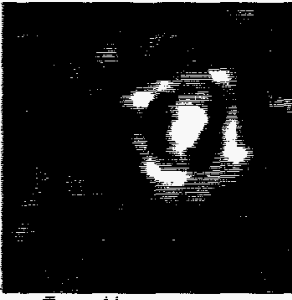

Depth $\approx 5 \mathrm{~cm}$

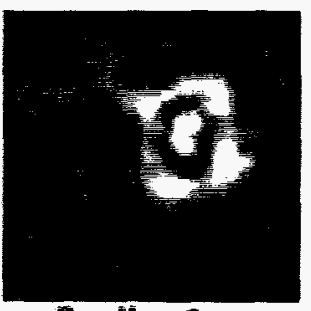

Depth $=6 \mathrm{~cm}$

(1a)

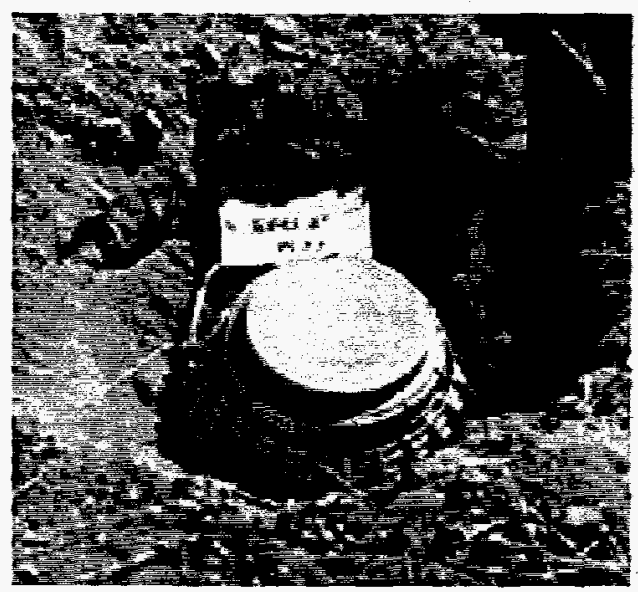

VS-2.2

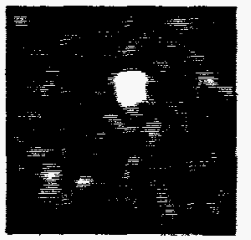

Depth-5.5 cm
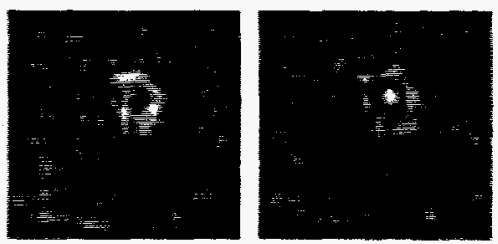

Depth $-7.6 \mathrm{~cm}$

Depth $-7.0 \mathrm{~cm}$

(1b)

Figures 1a snd 1b. Horizontal slices at various depths produce radar images of plastic mines 